\title{
BMJ Open Evaluation of a wearable wireless device with artificial intelligence, iThermonitor WT705, for continuous temperature monitoring for patients in surgical wards: a prospective comparative study
}

Yuwei Liu (D) , ${ }^{1,2}$ Changqing Liu, ${ }^{3}$ Min Gao, ${ }^{1}$ Yan Wang, ${ }^{1}$ Yangjing Bai, ${ }^{4}$ Ruihua Xu, ${ }^{1}$ Renrong Gong ${ }^{2,5}$

To cite: Liu Y, Liu C, Gao M, et al. Evaluation of a wearable wireless device with artificial intelligence, iThermonitor WT705, for continuous temperature monitoring for patients in surgical wards: a prospective comparative study. BMJ Open 2020;10:e039474. doi:10.1136/ bmjopen-2020-039474

- Prepublication history and additional material for this paper is available online. To view these files, please visit the journal online (http://dx.doi.org/10. 1136/bmjopen-2020-039474).

$\mathrm{RX}$ and $\mathrm{RG}$ contributed equally.

Received 21 April 2020

Revised 10 October 2020 Accepted 14 October 2020

Check for updates

(C) Author(s) (or their employer(s)) 2020. Re-use permitted under CC BY-NC. No commercial re-use. See rights and permissions. Published by BMJ.

For numbered affiliations see end of article.

Correspondence to Professor Renrong Gong; gongrenrong@wchscu.cn and Professor Ruihua Xu; xuruihua@wchscu.cn

\section{ABSTRACT}

Objectives To evaluate a new-generation, non-invasive, wireless axillary thermometer with artificial intelligence, iThermonitor (WT705, Raiing Medical, Beijing, China), and to ascertain its feasibility for perioperative continuous body temperature monitoring in surgical patients.

Setting Departments of Biliary Surgery and Operating Room and the post-anaesthesia care unit of a university teaching hospital in Chengdu, China.

Participants A total of 526 adult surgical patients were consecutively enrolled.

Design This was a prospective observational study. Axillary temperatures were continuously recorded with iThermonitor throughout the whole perioperative period. The temperatures of the contralateral armpit were measured with mercury thermometers at 8:00, 12:00, 16:00 and 20:00 every day and were used as references.

Outcome measures The outcomes were the accuracy and precision of the temperatures measured with iThermonitor, the validity to detect fever and the feasibility of continuous wear. Pairs of temperatures were evaluated with Student's t-test, Pearson's correlation and repeatedmeasures Bland-Altman plot.

Results A total of 3621 pairs of body temperatures were obtained. The temperatures measured with iThermonitor agreed with those measured with the mercury thermometers overall, with a mean difference of $0.03^{\circ} \mathrm{C} \pm 0.35^{\circ} \mathrm{C}$ and a moderate correlation $(r=0.755$, $\mathrm{p}<0.001)$. The $95 \%$ limits of agreement (LoA) ranged from $-0.63^{\circ} \mathrm{C}$ to $0.73^{\circ} \mathrm{C}$, with $5.11 \%$ of the differences outside the $95 \%$ LoA. The intraclass correlation coefficient was 0.753 . Continuous temperature monitoring captured more fevers than intermittent observation ( $117 / 526$ vs $91 / 526$, $\mathrm{p}<0.001$ ), detected fever up to 4.35 hours earlier, and captured a higher peak temperature $\left(0.29^{\circ} \mathrm{C} \pm 0.27^{\circ} \mathrm{C}, 95 \%\right.$ Cl: $0.26-0.31)$. All subjects felt that wearing iThermonitor was more or less comfortable and did not affect their daily activities.

Conclusions iThermonitor is promising for continuous remote temperature monitoring in surgical patients. However, further developments are still needed to improve the precision of this device, especially for temperature
Strengths and limitations of this study

- A wearable wireless device with artificial intelligence, iThermonitor WT705, was evaluated for continuous temperature monitoring in surgical patients.

- Axillary temperature was remotely monitored in different clinical scenarios throughout the whole perioperative period.

- More algorithm training and developments are still needed to improve the precision of this device, especially for temperature detection in underweight patients and those with lower body temperature.

- Only axillary temperatures were detected for the evaluation of iThermonitor.

- The validity of the device was not tested in the intensive care unit or in patients with compromised haemodynamics, which might change skin perfusion and temperature.

detection in underweight patients and those with lower body temperature.

Trial registration number ChiCTR1900024549; Results (registered on 5 July 2019).

\section{INTRODUCTION}

Body temperature is one of the most foundational vital signs of patients. Surgical patients are typically exposed to cold environments, administrations of unwarmed intravenous fluids, bacterial invasions and anaesthetic drugs that may impair the thermoregulatory system, ${ }^{1}$ leading to perturbations in body temperature. Accurately monitoring body temperature is essential for preventing hypothermia and detecting infectious complications in surgical patients. ${ }^{23}$

No ideal device has been developed yet ${ }^{4}$ to continuously monitor body temperature across different clinical settings with satisfactory accuracy, availability and affordability. ${ }^{5}$ 
Peripheral thermometers measuring temperature from the tympanic membrane, temporal artery, oral cavity, forehead or other parts are not considered to be stable or accurate enough. ${ }^{6-8}$ Inserts of a temperature probe to the oesophageal, pulmonary artery, nasopharynx, rectum or bladder can precisely and continuously detect the core temperature, ${ }^{9}$ but these invasive devices increase the risk of infection and are only used for patients in intensive care units (ICUs) and surgical patients under anaesthesia when necessary. ${ }^{10}{ }^{11}$ Currently, there is still an urgent need for thermometers that accurately and continuously monitor body temperature in clinical practice.

Wearable technology is changing the way that body temperatures have been measured and clinical care has been performed. ${ }^{12}$ In recent years, several wireless dermal wearable thermometers have increased the feasibility of continuous body temperature monitoring outside of the critical care setting. ${ }^{13}$ However, only a small proportion of wearable devices have a Conformité Européenne (CE) marking class II or above, or approval from the US Food and Drug Administration (FDA) as medical devices. ${ }^{14}$ There are still few options with convincing evidence to support their usage in clinical environments. ${ }^{15}$ Wearable devices reflecting skin temperatures have been proven to have strong bias and poor correlations with oral temperatures $^{16}$ or tympanic temperatures. ${ }^{17}$ Zsuzsanna Balla et $a l^{13}$ found seven wireless dermal thermometers reflecting core temperatures through internet searching, and tested four (FeverSmart, iThermonitorWT701, Quest Temp Sitter and Thermochron iButton) that were commercially available. The results indicated that they were not reliable or accurate enough for most types of clinical studies, although the iThermonitor WT701 system had the least unsatisfactory correlation to rectal thermometers. Moreover, surgical patients were typically transferred between multiple units of care (ie, surgical ward, operating room and post-anaesthesia care unit). Because of the challenges during scenario changes, such as tissue perfusion, physical activity, length of wearing time and different compliances between awake patients and those under anaesthesia, it remains unclear whether these devices are capable of continuous temperature monitoring across different clinical scenarios. In addition, battery life and internal storage space limit their application.

A new generation of the non-invasive, wireless axillary thermometer iThermonitor WT705 was developed with advanced versions of machine learning algorithms for continuous remote monitoring of body temperature (including core temperature) in different clinical settings. Although the previous version of iThermonitor has been reported to accurately represent core temperature (distal oesophagus temperature) in patients under anaesthesia, ${ }^{18}$ the performance of the latest version has not yet been tested in surgical wards. Therefore, we conducted a prospective study to assess the accuracy and feasibility of iThermonitor WT705 for testing body temperature in awake patients in surgical wards, and its potential for continuous monitoring of body temperature throughout the whole perioperative period at real clinical settings.

\section{METHODS}

\section{Study design, subjects and setting}

This was a prospective comparative descriptive study to evaluate iThermonitor for continuous temperature monitoring by comparing it with mercury thermometers. Patients admitted to the Department of Biliary Surgery at West China Hospital of Sichuan University were consecutively recruited for this study, from August 2019 to December 2019. The inclusion criterion was that the patient signed an informed consent form. Patients with any impediment to wearing the iThermonitor in their axillae were excluded. Finally, 526 patients were enrolled, and all signed informed written consent forms.

\section{Instruments}

The study instruments were as follows: (1) wireless, noninvasive dermal thermometer iThermonitor (model WT705, Raiing Medical Company, Beijing, China), with an accuracy of $\pm 0.1^{\circ} \mathrm{C}\left(5^{\circ} \mathrm{C}-40^{\circ} \mathrm{C}\right)$. This is a battery-operated reusable electronic device with 30 days of battery life. The FDA approved it as a class II medical device. iThermonitor was securely attached to the axilla (shaved if necessary) of patients with adhesive tape provided by the manufacturer (figure 1). iThermonitor WT705 was equipped with a more powerful chip developed from the previous version of WT701, which enables it to store more data with time and clinical scenario stamps. The sensor recorded the axillary temperature once every $4 \mathrm{~s}$ and then transmitted the raw data wirelessly to its associated signal repeater (cHub, Raiing Medical Company, Beijing, China). The cHub was attached to the bedside, with two versions of patented machine learning algorithms running inside. One version was for patients in the operating room to estimate core temperatures based on axillary temperatures. The other version was for patients in the ward and/ or home to test the axillary temperatures, as used in the present study. The algorithms were designed to improve the accuracy of temperature tests by adjusting for possible interference, including anaesthetics, daily activities, body posture changes, loose adhesive tape and/or ambient temperature, which could be preset as needed, together with the data output frequency. The average temperature per minute was transmitted wirelessly via Bluetooth or WiFi to the central computer in the nurse station. The dynamic temperature curves of all patients were visualised on the screen (online supplemental appendix figure 1). All iThermonitor sensors were proofread for accuracy according to the manufacturer's standard before use. (2) Mercury-in-glass thermometers were used (Riyue Medical Company, Chongqing, China) with an accuracy of $\pm 0.1^{\circ} \mathrm{C}$, over the range of $35^{\circ} \mathrm{C}-42^{\circ} \mathrm{C}$. Mercury thermometers were calibrated each week by comparison to a high-precision industrial mercury thermometer (HX-290, Chuangji Instruments Company, Hebei, China). Mercury 


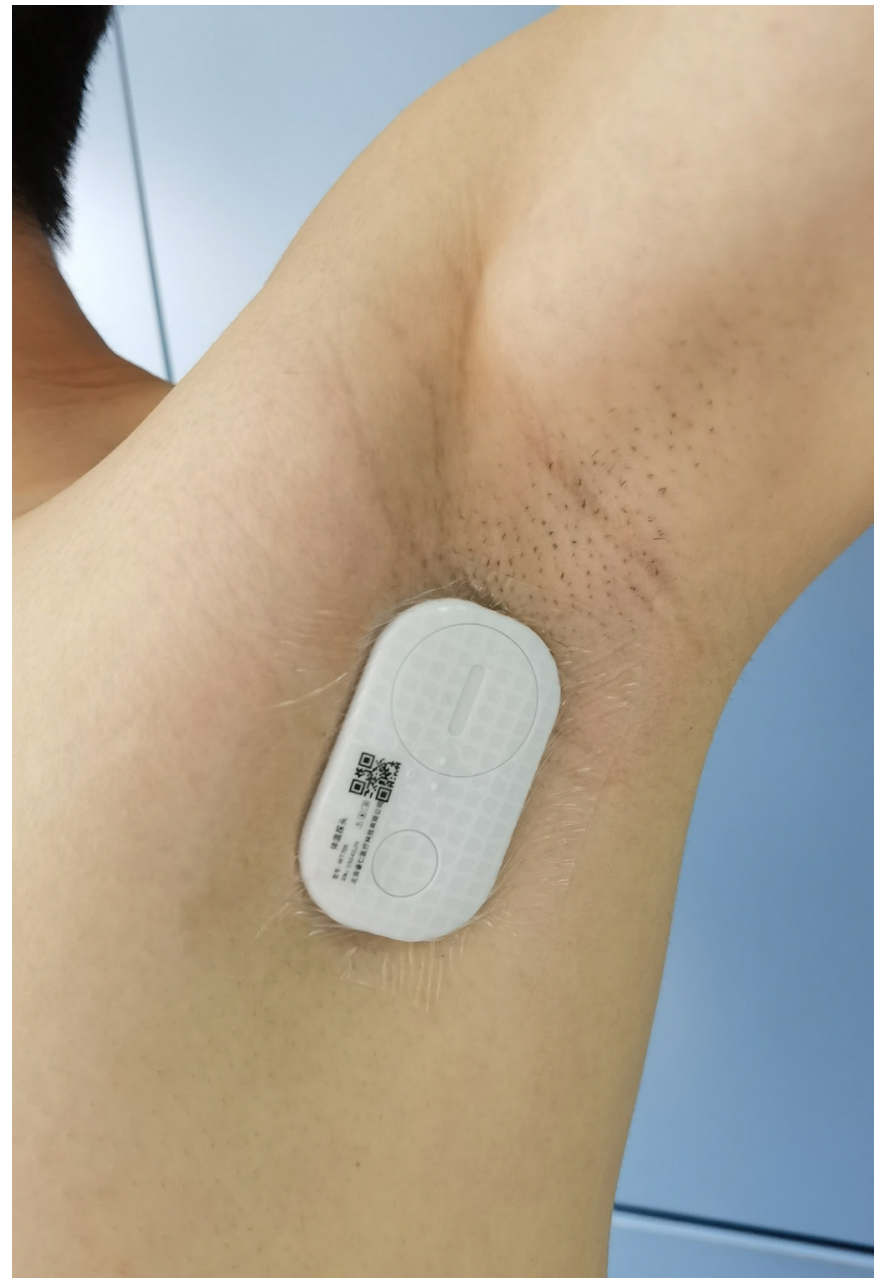

Figure 1 The position of the iThermonitor sensor in the axilla.

thermometers with temperature deviations greater than $0.2^{\circ} \mathrm{C}$ were not used. iThermonitor could be tested as a substitute choice for mercury thermometers since efforts have been made by countries to find alternative methods to mercury thermometers.

\section{Data collection}

Age, sex and body mass index (BMI) were extracted from the medical records. The iThermonitor sensor was attached to the dried and cleaned skin in the armpit region on the first day of admission to continuously record the body temperature throughout the whole perioperative period, except during a CT scan or a shower. The axillary skin was checked by registered nurses every day for local skin allergies or other adverse reactions. Patients were asked to complete a questionnaire (online supplemental appendix table 1) to evaluate the tolerability of iThermonitor on the day of discharge.

Temperature was measured with mercury thermometers at 8:00, 12:00, 16:00 and 20:00 every day; the 8:00 and 16:00 measurements were selected and paired with the temperatures measured with iThermonitor because two specially trained registered nurses were assigned to take these measurements during the day shift. One nurse measured the temperature with a mercury thermometer and recorded it together with the time of the measurement. The other nurse read the temperature detected with iThermonitor of the same patient at the same time from the central monitoring station. Meanwhile, activity, state of consciousness and armpit sweating were assessed and recorded.

Once the difference between the concurrent temperatures measured with the two devices was over $1^{\circ} \mathrm{C}$, the measurement was repeated immediately with a mercury thermometer, and the fit of iThermonitor was checked. When improper measurements or/and fit were confirmed, the corresponding sets of data were excluded. Only the differences were confirmed to truly exist, and the data were included for further analyses.

\section{Main end points}

The following endpoints were evaluated:

- Accuracy: the accuracy was expressed as the mean of the difference (also called bias) and the SD, as calculated by the temperature recorded with iThermonitor minus that recorded with a mercury thermometer. A priori, an absolute difference of $0.5^{\circ} \mathrm{C}$ was considered to be clinically acceptable. ${ }^{18} 19$

- Precision: precision (also called reliability) was tested by the $95 \%$ LoA and intraclass correlation coefficient (ICC). As in previous studies, ${ }^{17} 18$ the $95 \%$ LoA within $\pm 0.5^{\circ} \mathrm{C}$ and ICC greater than 0.7 were considered well accepted precisions.

- Validity: taking recordings of mercury thermometers as references, validity of the iThermonitor was evaluated by the ability to detect fever. Axillary temperatures of $38^{\circ} \mathrm{C}$ were considered a cut-off value of fever, according to the Brighton Collaboration Fever Working Group's definition. ${ }^{20}$ The peak temperatures recorded by the two methods were also compared. In addition, the first time iThermonitor indicated body temperatures exceeding $38^{\circ} \mathrm{C}$ (lasting at least $5 \mathrm{~min}$ ) was compared with the first time for a mercury thermometer to detect fever.

- Feasibility: the feasibility of continuous temperature monitoring was assessed with a comfort score (online supplemental appendix table 1) and possible adverse events. Any adverse events, such as skin blisters or ulcers caused by iThermonitor, or the breaking of a mercury thermometer, were included.

\section{Statistics}

Means and SD of temperatures were calculated for iThermonitor and mercury thermometers. Quantitative data are expressed as the mean \pm SD. Student's t-test for matched pairs, Pearson's correlation analysis and repeated-measures Bland-Altman plot were used to evaluate the relationship between the two sets of temperatures. The calculations of the Bland-Altman plot with multiple measurements per subject were performed as described by Bland $e t a l,{ }^{21}$ and the confidence intervals of 95\% LoA were estimated as described by Zou. ${ }^{22}$ Possible 
factors associated with the accuracy were estimated by multiple linear regression analysis, in which the differences between iThermonitor and mercury thermometer readings were considered the dependent variables, and all the factors considered were the explanatory variables. $\mathrm{P}<0.05$ was considered statistically significant. The data were analysed with Python V.3.5.1, and MedCalc V.19.1.3 software for repeated-measures Bland-Altman plot.

\section{Sample size considerations}

The sample size module for the Bland-Altman plot of MedCalc software was used to estimate the sample size. An expected mean of differences was set as $0.03^{\circ} \mathrm{C}$, with a $\mathrm{SD}$ of $0.23^{\circ} \mathrm{C}$, according to our previous pilot study. This calculation set a maximally allowed difference of $0.5^{\circ} \mathrm{C}$ (usually recognised as clinically significant), ${ }^{17} 18$ a type I error rate $(\alpha)$ of 0.05 , and a power of $80 \%$. Finally, 3292 pairs of data were deemed sufficient to detect a difference between iThermonitor and the mercury thermometers.

\section{Patient and public involvement}

No patients or members of the public were involved in the design of this study, the implementation of the study, or the dissemination of the results.

\section{RESULTS}

\section{Characteristics of the patients}

A total of 526 patients were enrolled. All of them completed the study and were included in the final analysis. No missing values needed to be processed. Each patient wore iThermonitor temperature sensor from admission to discharge, with an average of $3.37 \pm 2.95$ days. The cumulative monitoring duration was 1768 days. Temperature curves with time stamps across different clinical scenarios were recorded for each patient (online supplemental appendix figure 1). Among the 526 patients, there were $197(37.5 \%)$ men and $329(62.5 \%)$ women, with an average age of $53.47 \pm 14.46$ years (over the range of $15-86$ years). Patients were allowed to ambulate inside the hospital, although most patients remained at their bedsides for daily activities, due to their surgeries. The room temperature was $24.2^{\circ} \mathrm{C} \pm 1.3^{\circ} \mathrm{C}\left(22^{\circ} \mathrm{C}-26^{\circ} \mathrm{C}\right)$, maintained by the central air conditioning system in the hospital. Demographic characteristics are listed in table 1.

\section{Accuracy and precision of iThermonitor}

A total of 3621 pairs of body temperatures were obtained. The mean temperature measured with iThermonitor was $36.61^{\circ} \mathrm{C} \pm 0.49^{\circ} \mathrm{C}$, ranging from $34.8^{\circ} \mathrm{C}$ to $39.6^{\circ} \mathrm{C}$, while the mean temperature measured with the mercury thermometers was $36.58^{\circ} \mathrm{C} \pm 0.52^{\circ} \mathrm{C}$, ranging from $35.0^{\circ} \mathrm{C}$ to $39.9^{\circ} \mathrm{C}$. The mean of difference (bias) between the two methods was $0.03^{\circ} \mathrm{C} \pm 0.35^{\circ} \mathrm{C}$, ranging from $-1.40^{\circ} \mathrm{C}$ to $1.80^{\circ} \mathrm{C}$. The biases within $\pm 0.5^{\circ} \mathrm{C}$, the clinically acceptable standard defined by a priori, accounted for $87.68 \%$, while $99.17 \%$ were within $\pm 1.0^{\circ} \mathrm{C}$. A scatter plot shows a relatively strong linear correlation $(\mathrm{r}=0.755, \mathrm{p}<0.001)$ between the two

\begin{tabular}{lc}
\hline \multicolumn{1}{l}{ Table 1 Description of the patients } \\
\hline Variable & Summary \\
\hline Patient characteristics $\left(\mathrm{N}_{1}=526\right)$ & $53.47 \pm 14.46(15-86)$ \\
\hline Age (years) & $197(37.5 \%)$ \\
Sex & $329(62.5 \%)$ \\
\hline Man (\%) & $23.21 \pm 3.09(15.21-37.78)$ \\
Woman (\%) & $3.37 \pm 2.95(1--22)$ \\
\hline BMl (kg/m $\left.{ }^{2}\right)$ & 1768 \\
\hline Average monitor duration (days) & \\
Cumulative monitor duration (days) & \\
\hline Patient status when measuring temperature $\left(\mathrm{N}_{2}=3621\right)$ \\
\hline Mobility & $3490(96.38 \%)$ \\
\hline Bedridden & $131(3.62 \%)$ \\
\hline Off-bed activities & $3572(98.65 \%)$ \\
\hline Consciousness & $49(1.35 \%)$ \\
\hline Awake & $26(0.72 \%)$ \\
\hline Sleep
\end{tabular}

The data are presented as $n$ (\%) for categorical variables or the mean \pm SD for continuous variables.

BMI, body mass index; $\mathrm{N}_{1}$. number of patients; $\mathrm{N}_{2}$, number of paired temperature data sets.

groups of temperatures (online supplemental appendix figure 2). The Bland-Altman plot shows that the $95 \%$ LoA were broader than the predefined range, with the upper limit at $0.73^{\circ} \mathrm{C}$ and the lower limit at $-0.63^{\circ} \mathrm{C}$. Meanwhile, $5.11 \%(185 / 3621)$ of the points were outside the $95 \%$ LoA (figure 2). The ICC was 0.753 , indicating that the temperatures measured by the two methods moderately agreed overall.

\section{Factors associated with the difference between the two methods}

Possible factors associated with the difference in readings between iThermonitor and the mercury thermometers were evaluated by the multiple linear regression model (table 2). Readings of mercury thermometers, BMI and male sex were negatively correlated with the difference. Age, mobility, consciousness, length of wearing and sweating in the axilla were not significantly associated with the difference.

The effects of the associated factors were further evaluated for the differences between iThermonitor temperatures and mercury thermometer temperatures (table 3 ). The differences were significant when the readings of the mercury thermometers were below $36.0^{\circ} \mathrm{C}$ or $\geq 38.0^{\circ} \mathrm{C}$, but not significant between $36.0^{\circ} \mathrm{C}$ and $37.9^{\circ} \mathrm{C}$. Regarding the effects of sex, the iThermonitor readings compared with the mercury thermometer readings were significantly lower in male subjects but higher in female subjects. In addition, there were significant differences in patients with $\mathrm{BMI}<18.5 \mathrm{~kg} / \mathrm{m}^{2}$ or ranging from $18.5 \mathrm{~kg} / \mathrm{m}^{2}$ to 23.9 


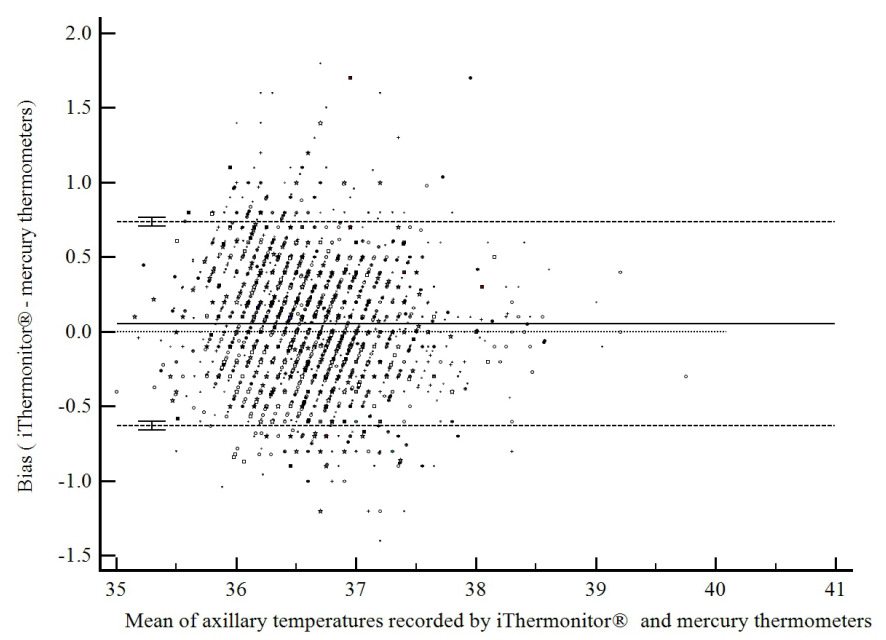

Figure 2 Repeated-measures Bland-Altman plot of iThermonitor axillary temperatures against mercury thermometer temperatures. ICC $=0.753,95 \%$ LoA were from $-0.63^{\circ} \mathrm{C}$ to $0.73^{\circ} \mathrm{C}$. A total of $5.11 \%$ of the points were outside the $95 \%$ LoA. ICC, intraclass correlation coefficient; LoA, limits of agreement.

$\mathrm{kg} / \mathrm{m}^{2}$, but not in those with BMI ranging from $24.0 \mathrm{~kg} /$ $\mathrm{m}^{2}$ to $27.9 \mathrm{~kg} / \mathrm{m}^{2}$ or $\geq 28.0 \mathrm{~kg} / \mathrm{m}^{2}$.

\section{Comparisons of the two methods in detecting fever}

Among the 526 patients, 117 were detected to have fever by continuous recordings with iThermonitor, while only 91 patients were detected by intermittent readings with mercury thermometers $\left(\chi^{2}\right.$ test for paired sample, $\mathrm{p}<0.001)$. A total of 124 patients were observed to have fevers with iThermonitor or the mercury thermometers, and 84 subjects were observed by both methods.

\section{Comparisons of average peak temperatures}

The average peak temperature captured by intermittent measurements with mercury thermometers was $37.26^{\circ} \mathrm{C} \pm 0.56^{\circ} \mathrm{C}$, whereas continuous monitoring with iThermonitor detected a higher peak temperature of $37.55^{\circ} \mathrm{C} \pm 0.59^{\circ} \mathrm{C}$. A mild but statistically significant difference of $0.29^{\circ} \mathrm{C} \pm 0.27^{\circ} \mathrm{C}$ (range from $-0.45^{\circ} \mathrm{C}$ to $1.26^{\circ} \mathrm{C}$, $95 \% \mathrm{CI}: 0.26^{\circ} \mathrm{C}-0.31^{\circ} \mathrm{C}$ ) was noted between the peak temperatures recorded by the two methods (figure 3 ).

\section{Comparison of the earliest time to detect fevers}

Continuous monitoring with iThermonitor detected fevers earlier than intermittent measurement with mercury thermometers. A mean time interval of 4.35 hours was observed, with a minimum difference of -0.92 hours and a maximum difference of 25.34 hours.

\section{Feasibility of continuous temperature monitoring}

During 1768 monitoring days, 4.37\% (23/526) of the patients complained of slight itching during the wearing period. Local skin redness was observed in two patients but resolved after iThermonitor was moved to the contralateral axilla. A comfort score from 1 to 5 was used to evaluate the feasibility of wearing iThermonitor, with 1 meaning most uncomfortable and intolerable and 5 meaning very comfortable. Of the 109 patients enrolled in August 2019 and September 2019, 21 selected a score of 2,81 selected a score of 3,6 selected a score of 4 and 1 selected a score of 5 . All subjects felt that wearing iThermonitor was more or less comfortable and did not affect their daily activities, indicating acceptable compliance of iThermonitor.

\section{DISCUSSION}

This was a prospective study to evaluate the performance of iThermonitor WT705, a wireless dermal temperature sensor, for continuous temperature monitoring in surgical patients. iThermonitor was selected because its performance had not been tested before for continuous temperature monitoring in surgical patients, although it has been one of the best performing devices among the available wireless dermal thermometers due to its

Table 2 Relationships of considered factors with the differences between iThermonitor temperatures and mercury thermometer temperatures*

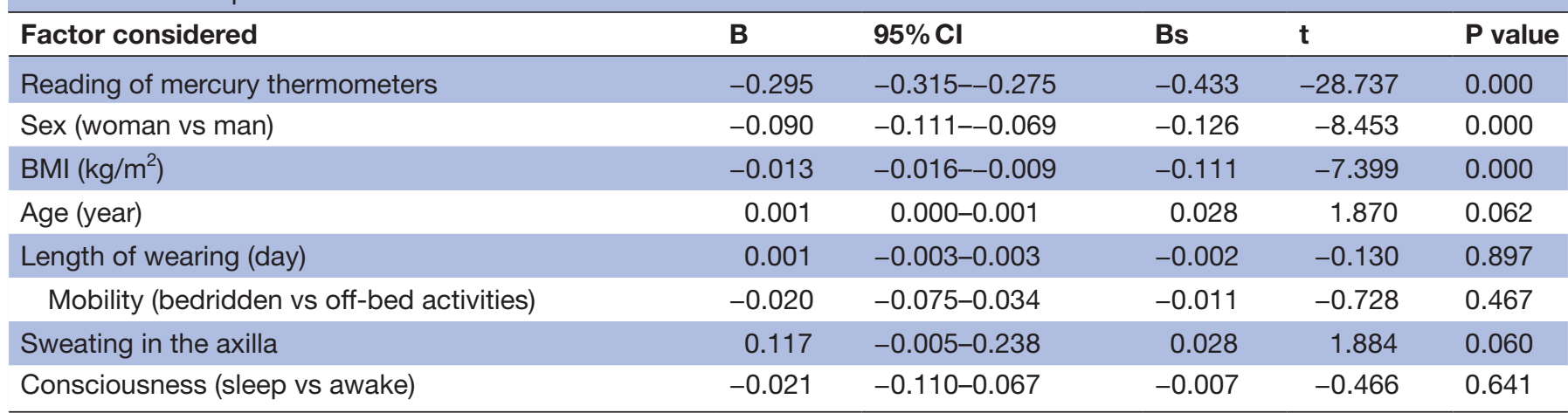

Estimated by multiple linear regression analysis with the dependent variable as the difference of iThermonitor temperatures minus mercury thermometer temperatures, with all the factors entered into the regression. B, linear regression coefficient. 95\% $\mathrm{Cl}$, 95\% $\mathrm{Cl}$ for linear regression coefficient. Bs, standardised coefficient.

${ }^{*}$ Squared variation coefficient $\mathrm{R}^{2}=0.215, \mathrm{~F}=123.474, \mathrm{P}<0.001$.

BMI, body mass index. 
Table 3 The effects of associated factors on the temperature differences calculated with iThermonitor readings minus mercury thermometer readings

\begin{tabular}{|c|c|c|c|c|c|c|c|}
\hline Factors & $\mathbf{N}^{*}$ & $\begin{array}{l}\text { iThermonitor } \\
\left({ }^{\circ} \mathrm{C}\right)\end{array}$ & $\begin{array}{l}\text { Mercury } \\
\text { thermometer }\left({ }^{\circ} \mathrm{C}\right)\end{array}$ & Bias $\left({ }^{\circ} \mathrm{C}\right)$ & $95 \% \mathrm{Cl}$ of bias & $\mathbf{t}$ & $\mathrm{P}$ value \\
\hline \multicolumn{8}{|c|}{ Readings of mercury thermometers } \\
\hline Normal $\left(36.0^{\circ} \mathrm{C}-37.9^{\circ} \mathrm{C}\right)$ & 3285 & $36.63 \pm 0.42$ & $36.62 \pm 0.42$ & $0.01 \pm 0.33$ & $-0.01-0.02$ & 0.979 & 0.327 \\
\hline Fever $\left(\geq 38.0^{\circ} \mathrm{C}\right)$ & 61 & $38.11 \pm 0.54$ & $38.27 \pm 0.36$ & $-0.17 \pm 0.35$ & $-0.26--0.08$ & -3.682 & 0.000 \\
\hline Woman & 2141 & $36.64 \pm 0.51$ & $36.57 \pm 0.54$ & $0.08 \pm 0.35$ & $0.06-0.09$ & 10.003 & 0.000 \\
\hline \multicolumn{8}{|l|}{ BMI $\left(\mathrm{kg} / \mathrm{m}^{2}\right)$} \\
\hline Low $(<18.5)$ & 187 & $36.74 \pm 0.42$ & $36.60 \pm 0.47$ & $0.14 \pm 0.34$ & $0.09-0.19$ & 5.368 & 0.000 \\
\hline Normal (18.5-23.9) & 2156 & $36.66 \pm 0.50$ & $36.63 \pm 0.53$ & $0.04 \pm 0.34$ & $0.02-0.05$ & 4.869 & 0.000 \\
\hline
\end{tabular}

${ }^{*}$ Number of paired temperature data sets.

†Estimated by Student's t-test for matched pairs.

relatively high sensitivity and robustness in reflecting core temperature. $^{13}$

\section{Principal findings in accuracy and precision}

iThermonitor was compared with mercury thermometers. An overall small bias $\left(0.03^{\circ} \mathrm{C} \pm 0.35^{\circ} \mathrm{C}\right.$, table 3$)$ and moderate correlation (figure 2) were observed between the two devices. Nevertheless, the analysis of $95 \%$ LoA indicated that the comparisons with a bias less than $\pm 0.5^{\circ} \mathrm{C}$ only accounted for $87.68 \%$. This discrepancy was shown to be associated with the readings of the mercury thermometers, sex and BMI. The largest bias $\left(0.38^{\circ} \mathrm{C} \pm 0.40^{\circ} \mathrm{C}\right)$ existed when the readings of the mercury thermometers were below $36^{\circ} \mathrm{C}$, with the readings of iThermonitor higher than those of the mercury thermometers (table 3 ). Errors might exist in manual measurements with mercury

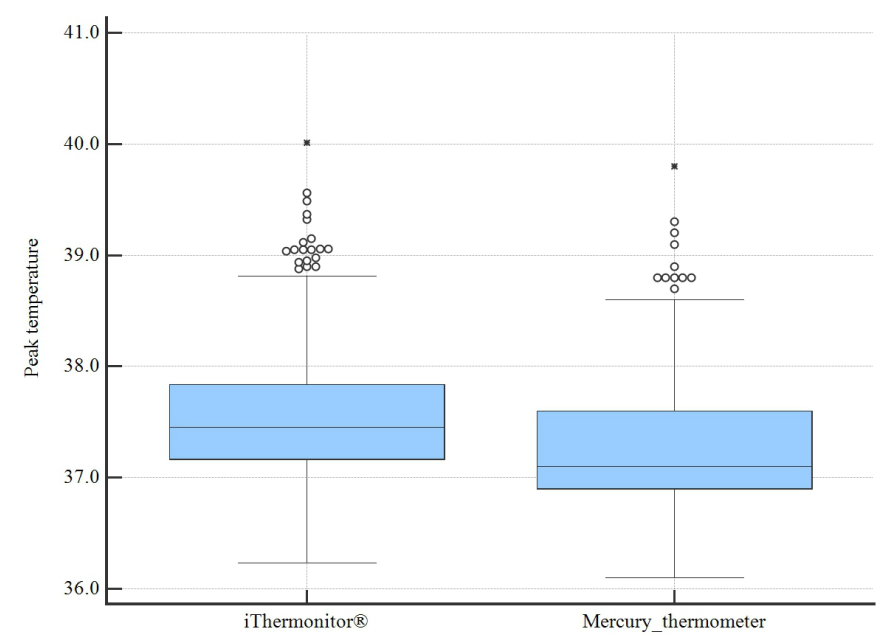

Figure 3 Peak temperatures recorded with iThermonitor and the mercury thermometers. thermometers if the patient did not maintain the proper measurement posture for enough time, leading to false body temperature readings below $36^{\circ} \mathrm{C}$. Stricter supervision and repeated measurements may improve the results when the readings of mercury thermometers are below $36^{\circ} \mathrm{C}$. On the other hand, the temperature output of iThermonitor may also be inaccurate, but it is difficult to distinguish which device, or both, is the main cause of the deviation. Moreover, not every reading of the mercury thermometers was double checked. This might also lead to biases. In addition, a significantly larger bias was also noticed in underweight patients (BMI $<18.5 \mathrm{~kg}$ / $\mathrm{m}^{2}$ ), but no significant differences were observed in overweight or obese patients (table 3 ). This result supports the earlier findings of Rubia-Rubia et al, ${ }^{23}$ who tested four axillary thermometers and found that the difference in readings between axillary thermometers and pulmonary artery temperatures increased with decreasing weight. A possible explanation is that underweight patients might have difficulty having thermometers properly attached to the axilla, leading to errors in the readings of axillary thermometers. Moreover, larger biases were observed in female patients (table 3). Evidence has indicated that there are sex differences in thermoregulatory mechanisms. Lu and $\mathrm{Dai}^{24}$ reported higher oral temperatures in older women than in men. Rubia-Rubia $e t a l^{23}$ found that male sex increased the bias between temperatures measured by digital axillary thermometer and core temperatures, although they were unable to find a satisfactory explanation.

\section{Compared to similar studies}

Different reference standards and algorithm versions have resulted in inconsistent accuracy of iThermonitor 
in previous reports. Pei et $a l^{18}$ tested the intraoperative version of iThermonitor WT701, and found that axillary temperature recordings well represented core temperatures in adults under anaesthesia with a mean difference of only $0.14^{\circ} \mathrm{C} \pm 0.26^{\circ} \mathrm{C}$ (oesophageal minus axillary) and $95 \% \mathrm{LoA}$ from $-0.38^{\circ} \mathrm{C}$ to $0.66^{\circ} \mathrm{C}$. It was also reported that iThermonitor WT701 rendered lower average temperatures than rectal temperatures (bias: $-0.77^{\circ} \mathrm{C} \pm 0.53^{\circ} \mathrm{C}$ ).$^{13}$ In addition, iThermonitor was highly easy to use to continuously monitor children's body temperatures at home. ${ }^{25}$ In the present study, the novel version of iThermonitor WT705 was selected and the algorithms were preset for ward/home use. The results demonstrated that iThermonitor could be used to continuously monitor temperatures in surgical patients, although improvements are still needed. Moreover, all subjects in the study felt that wearing iThermonitor was more or less comfortable and did not affect daily activities. This work adds evidence to support the applicability of iThermonitor in surgical wards as a continuation or extension of intraoperative temperature monitoring.

\section{Clinical implications}

The advantages and feasibility of continuous vital sign monitoring in general wards are attracting increasing attention. ${ }^{10}{ }^{26}$ Regarding body temperature monitoring, detecting the time to have fevers and the peak of fever are important for diagnoses and clinical decision-making. Dakappa $e$ a $\mathrm{l}^{11}$ noted a higher peak temperature with a significant difference of $1.52^{\circ} \mathrm{C}$ using a continuous tympanic temperature recording device (TherCom) than using mercury thermometers three times a day. Another study reported that a wearable digital thermometer (TremTraq, with a battery life of 72 hours) detected increases in body temperature 180 min earlier than the standard monitoring strategy. ${ }^{26}$ As claimed in a previous study, iThermonitor was marginally superior in following the individual trends than in assessing absolute temperatures. ${ }^{13}$ The present study demonstrated that continuous temperature monitoring with iThermonitor was better at capturing the peak of fever, and could detect fever 4.35 hours earlier than intermittent temperature monitoring. These findings may have important therapeutic implications. Furthermore, maintaining the continuity of body temperature monitoring across different clinical scenarios helps to instal a real-world database of a patient's perioperative body temperature, which would provide more information in exploring the regularity of perioperative temperature fluctuation.

Mercury-containing thermometers have been widely used for hundreds of years because of their stable performance in reflecting temperature. ${ }^{27}$ However, these glassbased thermometers are fragile, and mercury, which is one of the top 10 chemicals of major public health concern, can leak. ${ }^{28}$ Although the WHO has called for the phase out of mercury fever thermometers by $2020,{ }^{28}$ they are still widely used in many countries. ${ }^{59} 30$ Gaps are evident in practices on promoting mercury-free thermometers.
The lack of an ideal alternative device for temperature measurement is an important reason. Using iThermonitor instead of mercury thermometers to reduce medical mercury emissions is beneficial to patients, health personnel and public health. ${ }^{29} 30$

\section{Limitations}

There were several limitations in the present study. First, only axillary temperatures were detected using iThermonitor and mercury thermometers. Adding a set of core body temperatures would help better understand the validity of the device for monitoring body temperatures. Second, the validity of the device was not tested in the ICU or in patients with compromised haemodynamics, which might change skin perfusion and temperature. Third, armpits were randomly selected for temperature measurements, and the difference in armpit temperature between the dominant and non-dominant arms, which might not exist, ${ }^{23}$ was not taken into account. In addition, an axillary temperature of $38^{\circ} \mathrm{C}$ was set as a fever reference in the present study. However, the most convincing cut-off value remains unclear, due to varying definitions of fever. $^{73132}$

\section{CONCLUSIONS}

iThermonitor is a promising device for the continuous monitoring of temperature in surgical patients. This device can improve fever detection by dynamically reflecting the individual trends in body temperature throughout the whole perioperative period. However, more algorithm training is still needed to improve the accuracy of this device, especially when it is used in hypothermia or fever patients, female patients, or underweight or even normal-weight patients.

\section{Author affiliations}

${ }^{1}$ Department of Biliary Surgery, West China Hospital of Sichuan University, Chengdu, China

${ }^{2}$ West China School of Nursing, Sichuan University, Chengdu, P.R.China ${ }^{3}$ Operating Room of Anesthesia Surgery Center, West China Hospital of Sichuan University, Chengdu, P.R.China

${ }^{4}$ Department of Cardiac and Macrovascular Surgery, West China Hospital of Sichuan University, Chengdu, China

${ }^{5}$ Department of Surgery, West China Hospital of Sichuan University, Chengdu, P.R.China

Contributors YL participated in the conception, statistical analysis and manuscript draft preparation. CL was in charge of body temperature management in the operating room and post-anaesthesia care unit. MG and YW performed the temperature measurements. YB participated in the design of the study. RX administered the project. RG conceived, designed and managed the running of the study, interpreted the data and revised, and finally approved the manuscript. All authors read and approved the manuscript.

Funding This study was funded by the Sichuan University's West China Nursing Discipline Development Special Fund Project (No.HXHL19031).

Competing interests None declared.

Patient consent for publication Not required.

Ethics approval Ethical approval was obtained from the Biomedical Research Ethics Committee of West China Hospital of Sichuan University on 4 July 2019 (No. 2019-447). 
Provenance and peer review Not commissioned; externally peer reviewed.

Data availability statement Data are available upon reasonable request.

Supplemental material This content has been supplied by the author(s). It has not been vetted by BMJ Publishing Group Limited (BMJ) and may not have been peer-reviewed. Any opinions or recommendations discussed are solely those of the author(s) and are not endorsed by BMJ. BMJ disclaims all liability and responsibility arising from any reliance placed on the content. Where the content includes any translated material, BMJ does not warrant the accuracy and reliability of the translations (including but not limited to local regulations, clinical guidelines, terminology, drug names and drug dosages), and is not responsible for any error and/or omissions arising from translation and adaptation or otherwise.

Open access This is an open access article distributed in accordance with the Creative Commons Attribution Non Commercial (CC BY-NC 4.0) license, which permits others to distribute, remix, adapt, build upon this work non-commercially, and license their derivative works on different terms, provided the original work is properly cited, appropriate credit is given, any changes made indicated, and the use is non-commercial. See: http://creativecommons.org/licenses/by-nc/4.0/.

ORCID iD

Yuwei Liu http://orcid.org/0000-0002-9797-3153

\section{REFERENCES}

1 Sessler DI. Opioids and postoperative shivering. J Clin Anesth 2016;31:42-3.

2 Middleton S, McElduff P, Drury P, et al. Vital sign monitoring following stroke associated with 90-day independence: a secondary analysis of the QASC cluster randomized trial. Int J Nurs Stud 2019;89:72-9.

3 Larach MG, Brandom BW, Allen GC, et al. Malignant hyperthermia deaths related to inadequate temperature monitoring, 2007-2012. Anesthesia \& Analgesia 2014;119:1359-66.

4 Sollai S, Dani C, Berti E, et al. Performance of a non-contact infrared thermometer in healthy newborns. BMJ Open 2016;6:e008695.

5 Halder N, Peshin SS, Pandey RM, et al. Awareness assessment of harmful effects of mercury in a health care set-up in India: a surveybased study. Toxicol Ind Health 2015;31:1144-51.

6 Opersteny E, Anderson H, Bates J, et al. Precision, sensitivity and patient preference of non-invasive thermometers in a pediatric surgical acute care setting. J Pediatr Nurs 2017;35:36-41.

7 Niven DJ, Gaudet JE, Laupland KB, et al. Accuracy of peripheral thermometers for estimating temperature. Ann Intern Med 2015; $163: 768$.

8 Geijer H, Udumyan R, Lohse G, et al. Temperature measurements with a temporal scanner: systematic review and meta-analysis. BMJ Open 2016;6:e009509.

9 Calonder EM, Sendelbach S, Hodges JS, et al. Temperature measurement in patients undergoing colorectal surgery and gynecology surgery: a comparison of esophageal core, temporal artery, and oral methods. J Perianesth Nurs 2010;25:71-8.

10 Downey CL, Chapman S, Randell R, et al. The impact of continuous versus intermittent vital signs monitoring in hospitals: a systematic review and narrative synthesis. Int J Nurs Stud 2018;84:19-27.

11 Dakappa PH, Bhat GK, Bolumbu G, et al. Comparison of Conventional Mercury Thermometer and Continuous TherCom ${ }^{\circledR}$ Temperature Recording in Hospitalized Patients. J Clin Diagn Res 2016;10:OC43-6.

12 Liao Y, Thompson C, Peterson S, et al. The future of wearable technologies and remote monitoring in health care. Am Soc Clin Oncol Educ Book 2019;39:115-21.

13 Zsuzsanna Balla H, Theodorsson E, Ström JO. Evaluation of commercial, wireless dermal thermometers for surrogate measurements of core temperature. Scand J Clin Lab Invest 2019;79:1-6.

14 Muzny M, Henriksen A, Giordanengo A, et al. Wearable sensors with possibilities for data exchange: analyzing status and needs of different actors in mobile health monitoring systems. Int J Med Inform 2020;133:104017.

15 Breteler MJM, Huizinga E, van Loon K, et al. Reliability of wireless monitoring using a wearable patch sensor in high-risk surgical patients at a step-down unit in the Netherlands: a clinical validation study. BMJ Open 2018;8:e020162.

16 Izmailova ES, McLean IL, Bhatia G, et al. Evaluation of wearable digital devices in a phase I clinical trial. Clin Trans/ Sci 2019;12:247-56.

17 Downey C, Ng S, Jayne D, et al. Reliability of a wearable wireless patch for continuous remote monitoring of vital signs in patients recovering from major surgery: a clinical validation study from the tracing trial. BMJ Open 2019;9:e031150.

18 Pei L, Huang Y, Mao G, et al. Axillary temperature, as recorded by the iThermonitor WT701, well represents core temperature in adults having noncardiac surgery. Anesth Analg 2018;126:833-8.

19 Lu S-H, Dai Y-T, Yen C-J. The effects of measurement site and ambient temperature on body temperature values in healthy older adults: a cross-sectional comparative study. Int J Nurs Stud 2009;46:1415-22.

20 Marcy SM, Kohl KS, Dagan R, et al. Fever as an adverse event following immunization: case definition and guidelines of data collection, analysis, and presentation. Vaccine 2004;22:551-6.

21 Bland JM, Altman DG. Agreement between methods of measurement with multiple observations per individual. J Biopharm Stat 2007;17:571-82.

22 Zou GY. Confidence interval estimation for the Bland-Altman limits of agreement with multiple observations per individual. Stat Methods Med Res 2013;22:630-42.

23 Rubia-Rubia J, Arias A, Sierra A, et al. Measurement of body temperature in adult patients: comparative study of accuracy, reliability and validity of different devices. Int $J$ Nurs Stud 2011;48:872-80.

24 Lu S-H, Dai Y-T. Normal body temperature and the effects of age, sex, ambient temperature and body mass index on normal ora temperature: a prospective, comparative study. Int J Nurs Stud 2009;46:661-8.

25 Kakarmath SS, de Redon E, Centi AJ, et al. Assessing the usability of an automated continuous temperature monitoring device (iThermonitor) in pediatric patients: Non-Randomized pilot study. JMIR Pediatr Parent 2018;1:e10804.

26 Abbasi J. Wearable digital thermometer improves fever detection. JAMA 2017;318:510.

27 Wright WF, Mackowiak PA, Origin MPA. Origin, evolution and clinical application of the thermometer. Am J Med Sci 2016;351:526-34.

$28 \mathrm{WHO}$. WHO calls for the phase out of mercury fever thermometers and blood pressure measuring devices by 2020. Available: https:// www.who.int/news-room/detail/11-10-2013-who-calls-for-thephase-out-of-mercury-fever-thermometers-and-blood-pressuremeasuring-devices-by-2020 [Accessed 11 Oct 2013].

29 Li P, Yang Y, Xiong W. Impacts of mercury pollution controls on atmospheric mercury concentration and occupational mercury exposure in a hospital. Biol Trace Elem Res 2015;168:330-4.

30 Chadli-Debbiche A, Allani R, Jouini R, et al. Mercurial Hospital waste: management, becoming and recommendations. Tunis Med 2018;96:273-80.

31 Apa H, Gözmen S, Bayram N, et al. Clinical accuracy of tympanic thermometer and noncontact infrared skin thermometer in pediatric practice: an alternative for axillary digital thermometer. Pediatr Emerg Care 2013;29:992-7.

32 Wright WF, Auwaerter PG. Fever and fever of unknown origin: review, recent advances, and Lingering dogma. Open Forum Infect Dis 2020;7:ofaa132. 